\title{
TRABALHO FONOAUDIOLÓGICO COM GAGUEIRA NUMA PERSPECTIVA DISCURSIVA: UM ESTUDO DE CASO
}

\author{
Gabriela Valle Vasconcelos \\ Maria Janaina Alencar Sampaio
}

\begin{abstract}
RESUMO
Tendo em vista a carência de estudos que contemplem a gagueira do ponto de vista discursivo, fazse mister dar continuidade às pesquisas relacionadas a essa temática abordada por Azevedo (2000), em seu estudo acerca do funcionamento discursivo do sujeito gago. Sua pesquisa toma como base teórica, à teoria interacionista em aquisição de linguagem e a análise de discurso de linha francesa. A primeira embasa sua concepção a respeito da origem da gagueira e seu funcionamento enquanto linguagem e a segunda é utilizada como instrumento de análise, haja vista que Azevedo compreende a gagueira como atravessada pela ideologia. Neste trabalho nos propomos a fazer uma análise de um caso clínico de gagueira, observando as relações discursivas que se estabelecem entre terapeuta e paciente e como estas podem interferir no deslizamento ou não do discurso do sujeito gago, à luz dos estudos de Nadia Azevedo (2000), mestre em Fonoaudiologia, que se propõe a olhar a gagueira como um problema discursivo, diretamente relacionado às condições de produção.
\end{abstract}

PALAVRAS-CHAVE

Gagueira; Discurso; Linguagem

\section{SPEECH TERAPY ON STUTTERING IN A DISCURSIVE PERSPECTIVE: A CASE STUDY}

\begin{abstract}
With the lack of studies that include stuttering on the discursive point of view, it's important to continue the researches related to that theme approached by Azevedo (2000), on her study about the discursive functioning of the stutterer subject. Her research has as a theoretical base, the interactionist theory on language acquisition and the speech analysis on the french line of work. The first basis it's concept on the stuttering origin and it's functioning as language and the second is used as analysis tool, since Azevedo acknowledges stuttering as being crossed by the ideology. In this paper we propose an analysis of a clinical case of stuttering, observing the discursive relations that are established between the therapist and the patient and as these may interfere in the sliding of the stutterer subject speech, under the studies of Nadia Azevedo (2000), masters in speech therapy, the proposes to look to stuttering as a discursive problem, directly related to the production conditions.
\end{abstract}

\section{KEYWORDS}

Stuttering; Speech; Language

(c) ETD - Educação Temática Digital , Campinas, v.9, n.1, p.361-374, dez. 2007 - ISSN: 1676-2592. 


\section{O PROJETO INTERACIONISTA EM AQUISIÇÃO DE LINGUAGEM}

A teoria interacionista em aquisição de linguagem traz uma nova perspectiva a respeito do funcionamento da linguagem, onde esta é tida como constitutiva do sujeito, ou seja, o sujeito se constitui na/pela linguagem.

Cláudia De Lemos (1982), fundadora desta teoria, utilizou elementos teóricos da Psicolingüística e toma como unidade de análise mínima para o processo de aquisição de linguagem, o diálogo. No início de seus estudos, De Lemos, através da análise do "processo dialógico" ${ }^{1}$ entre mãe-criança, observou três processos nesta atividade: especularidade, complementaridade e reciprocidade.

No processo de especularidade o adulto atribui sentido à fala da criança espelhando-a, a partir disso a criança retoma a fala do adulto, especulando e fazendo novas produções.

No processo de complementaridade a criança ou o adulto retoma fragmentos da fala do outro e complementa com seus próprios enunciados.

No último processo, o de reciprocidade, a criança assume seu papel dialógico, tornando-se interlocutora no discurso.

De Lemos (1992) para dar suporte empírico ao seu modelo interacionista redireciona seus estudos e faz uma releitura de Saussure, Lacan e Jakobson, considerando a interação do sujeito com o outro como fundante da linguagem. Aponta para a interação adulto-criança como lugar de reflexão sobre os vários aspectos da construção da linguagem pela criança.

A partir de então os estudos sobre aquisição de linguagem voltam-se para uma lingüística tocada pela psicanálise onde o sujeito interage com o outro e é assujeitado pela linguagem.

De acordo com esta teoria, "o sujeito nasce no campo da linguagem" (DE VITTO, 1998, p. 22), tendo, já a partir do nascimento uma relação de intersubjetividade com o Outro. É através da interpretação das ações da criança pelo Outro que a linguagem assume seus significados e assim, a criança passa a ser representada como interlocutor, como sujeito. Em relação à interpretação Orlandi (1996, p. 22) diz: "O espaço de interpretação é o espaço do possível, da falha, do efeito metafórico, do equívoco, em suma: do trabalho de história e do significante, em outras palavras, do trabalho do sujeito".

\footnotetext{
${ }^{1}$ Este termo não é mais utilizado por De Lemos (1999), sendo substituído por interação.
} 
Durante o processo de aquisição de linguagem os significantes do adulto são incorporados pela criança e promovem transformações em sua fala. Sendo assim, vemos a importância do adulto diante da relação com a criança, visto que, a fala daquele está inserida na linguagem desta.

Antes mesmo do nascimento da criança, ela já é falada pelo outro, já existe de forma ativa dentro do discurso do outro que assume o papel de locutor e interlocutor no discurso.

No início da aquisição de linguagem, a criança é personagem de seu discurso, pois é falada pela mãe que responde pelo bebê respeitando os espaços de interlocução.

\begin{abstract}
Antes mesmo da emergência das primeiras formas lexicais estáveis no corpus da criança mais nova, vocalizações com um contorno prosódico significativo, em respostas à atividade verbal interpretativa da mãe, dava ao intercâmbio mãecriança uma aparência dialógica, indicativa do que naquele momento, se chamava de “competência comunicativa². (DE LEMOS, 1989, p.63).
\end{abstract}

A interação “é uma condição necessária” (DE LEMOS, 1992, p.128), pois o outro, como meio de movimentação da língua, estabelece uma relação social, propiciando a aquisição da linguagem da criança. Esta relação social se dá através da matriz de significações constituída pelos processos de interação realizados pela criança.

De Lemos baseia-se em Lacan (DOR, 1992) que, fazendo uma releitura da Teoria do Valor ${ }^{3}$, afirma que os elementos da língua têm um valor relativo. Isto quer dizer que cada elemento só tem valor pela relação que estabelece com outro elemento, contrapondose a Saussure que afirma que cada elemento da língua vale uma unidade de dupla face, significante e significado que constitui um signo.

Para Saussure, o sentido se dá através da relação entre significante e significado. Porém Lacan acredita na primazia do significante, concebendo o sentido como uma relação estabelecida entre um significante e outro significante, pois acredita que o significante permite acesso a um determinado sentido que não está unido a ele.

Para Saussure existe uma separação entre língua e fala (langue e parole), Lacan nega essa dicotomia, pois acredita que não há fala sem língua. Ele retoma essa dicotomia, discutindo o funcionamento da língua e da fala para se pensar na linguagem. Ele rediscute a linguagem junto à questão do sujeito, olhando o sujeito e a linguagem numa relação de

\footnotetext{
${ }^{2}$ Este termo não é mais utilizado por De Lemos (1999), sendo substituído por linguagem.

${ }^{3}$ Proposta por Saussure (1987, p. 104), afirma que na língua cada termo tem o seu valor em oposição aos outros termos. Para ele, o sistema é sempre momentâneo, isto é, varia de uma posição para a outra. Os valores, então, dependem de uma "convenção imutável".
} 
assujeitamento.

Lacan acredita que o sujeito é assujeitado pela linguagem, ou seja, é falado por essa linguagem e só fala aquilo que ela permite que ele fale porque o sujeito só pode falar aquilo que a língua autoriza, é significado pela linguagem.

Estudando a dicotomia língua e fala, Saussure (1987) identifica dois eixos da língua: eixo paradigmático, representado pela seleção de palavras que formam a frase, e eixo sintagmático, constituído pela combinação de paradigmas. O funcionamento da linguagem se daria formando um conjunto de paradigmas para se obter um sintagma.

Jakobson vem fazer uma releitura dos eixos paradigmático e sintagmático, aproximando-se das figuras da retórica, transformando-os em eixos metafóricos e metonímicos. O eixo metafórico corresponde às substituições e o eixo metonímico às combinações. Um sintagma combina vários elementos entre si, porém um paradigma pode ser substituído por outro, onde sempre na escolha de uma metáfora fica algo do elemento não escolhido em sua posição. Portanto é na substituição (metáfora) que há o movimento que explica o funcionamento da linguagem.

As relações no eixo metafórico ocorrem em ausência, pois ao se selecionar um elemento, obrigatoriamente se exclui outro. As relações no eixo metonímico se dão na presença de um elemento com o outro na mesma cadeia. Os movimentos desses eixos ocorrem simultaneamente.

No estudo sobre a aquisição de linguagem, De Lemos (1995) faz uma reinterpretação dos processos metafóricos e metonímicos trazendo-os para o funcionamento da linguagem.

Os processos metafóricos e metonímicos são leis de composição interna da ordem própria da linguagem e modos de emergência do sujeito na cadeia significante. São esses processos que possibilitam a (re)significação dos significantes da criança que circulam no discurso.

Deve-se, então, interpretar a fala da criança a partir das relações de (re)significação estabelecidas pelo adulto. Este movimento constitui um "mecanismo de mudança” (DE LEMOS, 1999, P.9) tanto do ponto de vista lingüístico e subjetivo, quanto da própria posição da criança na língua.

Sendo assim os processos metonímicos ocorrem em relações de presença, pois um significante tem valor determinado pela interpretação de outros significantes que se opõem no processo discursivo. Os processos metafóricos se dão em operação de substituição, dentro do discurso, pois uma palavra pode ser substituída por outra sinônima. A metáfora 
guarda em si conteúdos não-ditos, pois se estabelece em ausência.

Abaixo um esquema dos eixos metafórico e metonímico (AZEVEDO, 2000, p.25):

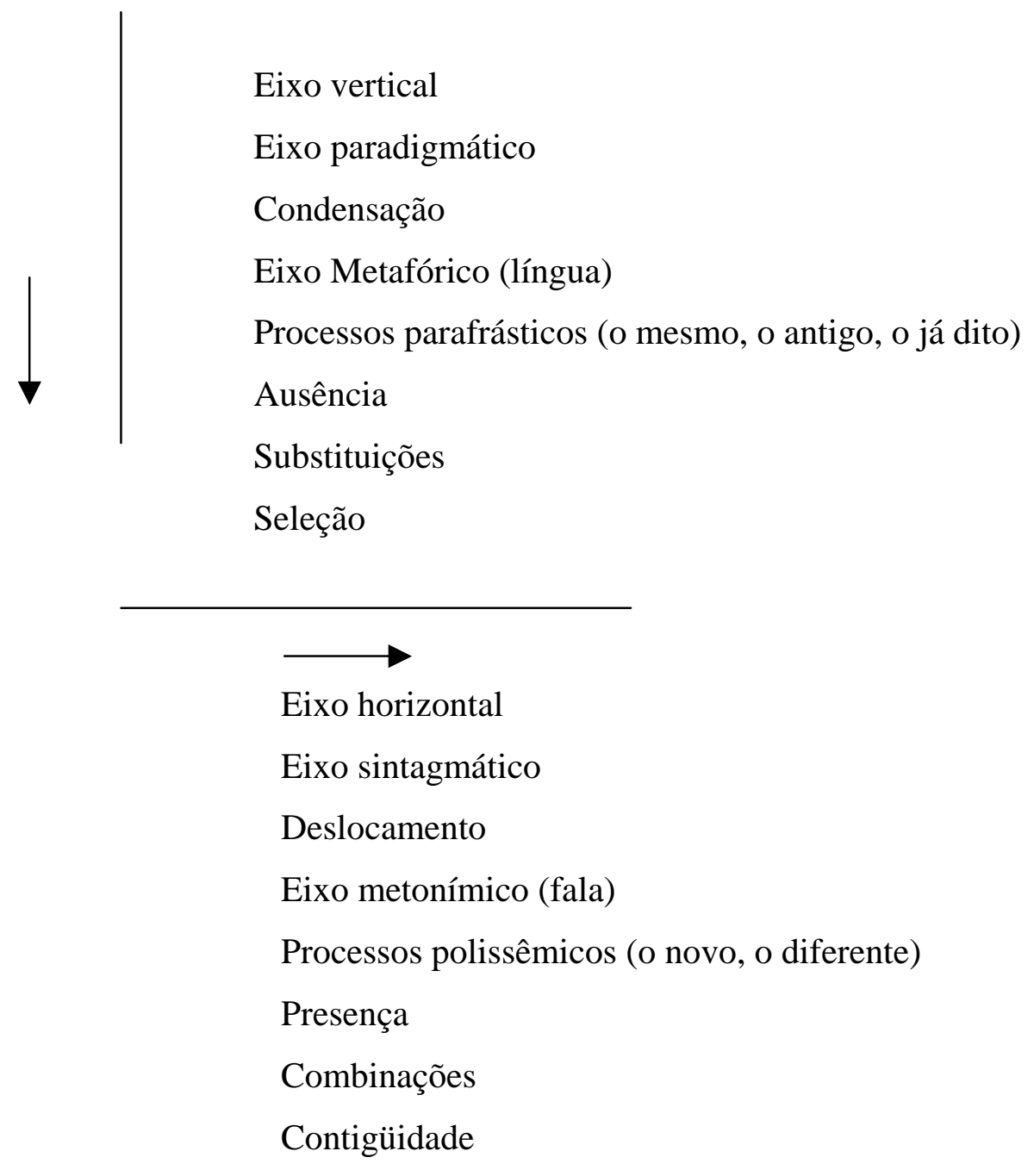

De Lemos (1999) aponta para uma relação entre processos metafóricos e metonímicos, com maior incidência de um ou de outro, demonstrando um novo olhar para o processo de aquisição de linguagem, onde se sobressai à relação da criança com o outro e com a própria língua.

Quando a mãe fala pela criança, ela atribui sentido aos significantes da criança o que gera um efeito de fala na criança. O bebê se utiliza da combinação de restos metonímicos da mãe que migram para o seu discurso pois ainda não desliza no eixo metafórico de funcionamento da linguagem. A interlocução é responsável pela construção de sentidos. 
Quando não há intervenção do outro, a linguagem funciona de maneira aberta. A partir da entrada do outro, existe uma harmonia discursiva entre os eixos. O interlocutor fecha o deslizamento no eixo metonímico. O corte incide no eixo metafórico onde se vai modificar o que se fala.

Num momento posterior a fala da mãe começa a gerar efeito na criança que incorpora os fragmentos de fala de sua mãe deslizando no eixo metonímico. O deslizamento no eixo metafórico se dá quando a criança começa a selecionar, dentre vários significantes, um possível para determinada situação discursiva.

Esses processos (metafóricos e metonímicos) podem ser descritos pelas posições que a criança assume na linguagem. Na primeira posição de falante, a mãe oferece a sua atividade de fala como espelho para a criança e para si própria, como intérprete e interlocutora. Temos assim, que a criança ainda não se encontra como autora do seu próprio discurso. Na segunda posição, através dos enunciados do adulto, a resposta da criança passa a preencher um papel semântico, sintático, pragmático. O enunciado da criança, então, resulta da incorporação do enunciado do adulto e da sua complementação de vocábulos e pensamentos. Por fim, na terceira posição, temos, através da interação com o Outro, a própria instanciação da criança na linguagem, isto é, o sujeito passa a produzir episódios interpretáveis como resposta à perspectiva instaurada pelo outro mais experiente.

Fazendo uma releitura da curva-em-U proposta pela Psicologia do Desenvolvimento, De Lemos (1999) utilizou os processos metafóricos e metonímicos para identificar três posições não hierárquicas da criança na língua.

Enquanto a criança fala, seus significantes a estão colocando em várias posições diferentes, ou seja, a cada formação discursiva, a criança está mudando de posição.

Como a língua é opaca, ou seja, exige a interpretação do outro, a criança é interpretada de várias formas diferentes o tempo todo.

Segundo De Lemos (1999) nesta abordagem o funcionamento da linguagem se dá através de uma mudança de posição em uma estrutura cujos pólos são o outro, a língua e o próprio sujeito. Em cada posição discursiva ocorre a dominância de um desses pólos. $\mathrm{O}$ erro refere-se a uma mudança na reorganização do conhecimento da criança, sendo visto como acerto, percorrendo três posições do ponto de vista do funcionamento da linguagem.

Na primeira posição, temos a fala da criança circunscrita à fala do adulto. A fala do outro é espelho para a criança e para o próprio sujeito que é intérprete e interlocutor. Nesta posição a criança acerta, não sendo autora do seu próprio discurso e deslizando 
predominantemente no eixo metonímico. O outro deve reconhecer os fragmentos discursivos da criança como linguagem, significando-os e os fazendo circular. Existe a dominância do pólo do outro; a criança falante está alienada na fala do outro, sendo por ela falada. Importa a escuta do outro para fazer o recorte e promover na criança o deslizamento, o que a criança fala precisa ser reconhecido como linguagem pelo outro; fragmentos do outro migram para fala da criança; a fala da criança está “presa” à fala do outro; ela incorpora fragmentos da fala do interlocutor e por isso parece "acertar”.

Na segunda posição, a criança se submete ao movimento da língua, é impermeável à entrada do outro, não há como agir sobre o discurso da criança nesse momento. Neste momento a criança erra demonstrando o funcionamento dos eixos da linguagem onde faz um movimento de substituição na língua. O erro caracteriza a independência discursiva da criança. Nessa posição de falante, o pólo dominante é a língua e seu funcionamento, que está apreensível através do fenômeno tratado como erro ou violação das leis e normas da língua. Segundo Azevedo (2003) os erros na fala da criança mostram um falante submetido ao movimento da língua, considerando "os processos metafóricos e metonímicos como circunscritos a um efeito de semelhança ou espelhamento entre cadeias que, ainda que originária do outro, ganhavam seu estatuto na língua, a saber, fora da esfera do outro”. A criança é resistente, ou seja, não vê diferença entre a sua fala e a fala do outro; não há um estranhamento na sua interpretação do que diz; não escuta na fala do outro a diferença; a criança começa a fazer substituições e a caminhar na sua posição na língua, mas é uma posição fixa, cristalizada (erro), não se desloca, é impermeável à correção do outro. O erro na fala da criança é a primeira forma de separação entre a sua fala e a fala do outro, a criança passa a ser autora do seu discurso e não um personagem, como na primeira posição.

Na terceira posição, aparece um estado mais “estável”, onde a criança passa a se autocorrigir e fazer reformulações a partir da entrada do interlocutor, está suscetível à interpretação da fala do outro. "Há um desaparecimento dos erros, o que coincide com a ocorrência de pausas, reformulações e autocorreções, com o reconhecimento dos erros, o que demonstra um deslocamento do sujeito falante em relação à sua fala e à fala do outro” (AZEVEDO, 2003, p.147). Nesta terceira posição, a criança passa de interpretada para intérprete, assume a autoria de seu próprio discurso. O pólo dominante é o do sujeito, este está dividido entre o que fala e o que escuta. Há um movimento constante de assemelhamento à fala do outro. 


\section{ANÁLISE DO DISCURSO}

A AD utiliza concepções do materialismo histórico, da lingüística e da psicanálise, porém interroga essas áreas de conhecimento a respeito de questões não respondidas por elas; a saber: "questiona a lingüística por deixar de lado a historicidade, o marxismo por não considerar o simbólico e a psicanálise por não compreender a ideologia absorvida pelo inconsciente”. (AZEVEDO, 2000, p. 27).

A AD propõe a noção de funcionamento discursivo levando em conta as condições de produção que são seu conceito básico. As condições de produção como diz Azevedo (2000) são formações imaginárias que apresentam: a relação de forças que se refere ao lugar de onde o sujeito fala, tendo relação com a hierarquia; a relação de sentido que remete ao fato de que todo discurso já foi anteriormente dito, ou seja, não existe discurso inédito; e a noção de antecipação que se trata da representação que o sujeito tem sobre a idéia que o outro faz a seu respeito.

Azevedo considera também importante para a compreensão do discurso gago o conceito de silenciamento. Que significa que o dizer é interditado e o discurso torna-se autoritário, sem reversibilidade, "ao dizer, o sujeito não diz ou diz outros sentidos" (AZEVEDO, 2000, p. 30).

Articulando essas duas concepções teóricas, Azevedo levanta três pontos essenciais em relação à gagueira do ponto de vista lingüístico-discursivo: a origem da gagueira, o lugar da gagueira e a tensão língua e fala.

Sobre a origem da gagueira, a autora considera a terceira posição de falante como um possível lugar para se pensar a origem da gagueira, pois é nessa posição que se observa o movimento de assemelhamento a fala do outro e conseqüentemente surgem as hesitações, repetições, autocorreções etc. na fala da criança, que podem gerar um efeito de gagueira, com isso, a criança pode ser levada a calar-se ou utilizar estratégias variadas como piscar os olhos, apertar as mãos, etc. a criança se depara com o não assemelhamento e é deslocada para a posição de sujeito gago, silenciado pelo outro.

Em relação ao lugar da gagueira, Azevedo considera que esta não está nem no sujeito nem no ouvinte, mas sim no discurso. Contrapondo-se à concepção que o sujeito gago tem desse lugar, ou seja, para ele a gagueira está localizada em seu próprio corpo, na língua ou no outro. O sujeito gago representa o outro como aquele que o interpreta como gago, remetendo à questão da antecipação.

Enfim, a tensão língua e fala existe no discurso de todos os sujeitos e é estruturante 
do dizer. Porém, no sujeito gago, esse desequilíbrio gera um estranhamento no outro, levando o sujeito a aprisionar-se na língua, privilegiando a forma em detrimento do conteúdo. Sendo assim, o sujeito fica aprisionado à língua, ou é silenciado pelas condições de produção do discurso.

\section{OBJETIVO, JUSTIFICATIVA E MÉTODO}

Neste trabalho nos propomos a fazer uma análise de um caso clínico de gagueira, à luz dos estudos de Nadia Azevedo (2000), mestre em Fonoaudiologia, que se propõe a olhar a gagueira como um problema discursivo, diretamente relacionado às condições de produção, conforme referimos anteriormente na introdução.

Tendo em vista a carência de estudos que contemplem a gagueira do ponto de vista discursivo, faz-se necessário analisar as relações discursivas que se estabelecem entre terapeuta e paciente e como estas podem interferir no deslizamento ou não do discurso do sujeito gago.

Trata-se de uma pesquisa descritiva-descritiva: estudo de caso. O sujeito desse estudo, um rapaz de 23 anos, o qual chamaremos "P.", procurou a clínicaescola de fonoaudiologia, da Universidade Católica de Pernambuco com queixa de gagueira, onde permaneceu em terapia por 3 anos. Durante este período, P. foi atendido por três terapeutas diferentes. Nossa análise se deu em recortes de sessões realizadas com a segunda terapeuta, que o atendeu durante o período de um ano.

As sessões foram gravadas em fitas $\mathrm{K} 7$ e transcritas por inteiro, para posteriormente selecionarmos os recortes discursivos a serem analisados. Foram selecionados, recortes de duas sessões.

\section{DISCUSSÃO}

Análise dos Recortes:

Legenda:

$\mathrm{T}=$ terapeuta;

$\mathrm{P}=$ paciente.

\section{Recorte Discursivo 1:}

P1: Assim a_a_s dificuldades né?

T1: Eu queria que você falasse pra mim dessa dificuldade tua, como é que é essa dificuldade pra você?

P2: É assim é_, a força pra_ pra falar eu nã_sai a pa_/ palavra a / ai eu tenho que botar uma força. 
T2: Como é que é essa força?

P3: É como se fosse um bloqueio é sem é_as vezes quan_do eu falo tem que forçar um pouco pra ela sai e_e_e_e é / é / é / é / é as vezes que eu falo uma sí_laba bem extensa ,é, um__prolongamento.

Em P1 o sujeito fala das disfluências, as quais atribui a metáfora "dificuldades". Podemos observar que em $\mathrm{T} 1$, a terapeuta devolve a fala de P. possibilitando um deslizamento no eixo metonímico e conseqüente abertura do discurso, como observamos em P2 o deslocamento para o significante "força". Em T2 a terapeuta realiza o estranhamento, para que P faça a abertura dessa metáfora, o que ocorre em P3, quando o sujeito se desloca de "força" para "bloqueio".

Neste recorte podemos observar que a terapeuta intervém na fala do sujeito de modo a promover deslizamentos e deslocamentos, pois partindo do pressuposto de que a língua é opaca, se faz necessário propiciar situações discursivas em que o sujeito possa abrir as metáforas em circulação, para que elas possam significar.

\section{Recorte Discursivo 2:}

P4: Sai, mas as_vezes quan__do a_a / a não sa_i tento é__ trocá palavra é__ bota outra é__ outra no lugar.

T3: Há você troca as palavras?

P5: I___ isso quando eu boto força e ela não sai.

T4: Aí quando você bota força e ela não sai você troca?

P6: É.

T5: E aí, funciona?

P7: a / a / acho que__às vezes sim.

T6: Em que vezes funciona?

P8: Quando não tem assim, uma vez específica não. Às vezes que eu falo assim sem / se__m essa força, ma / mas tem vezes que eu fa / que / que / que / a__ fa__ / fala não sai, ai boto u / uma_ / uma força ai / a / às vezes sai e / e tem_ vezes que não sai. Eu tento é_trocá. É como se fosse um truque não é?!

Neste segundo recorte $\mathrm{P}$. fala a respeito de um artifício que utiliza quando percebe que vai gaguejar: a troca de palavras. Podemos perceber em P4 que um possível significante "palavra" foi omitido do discurso quando P provavelmente percebeu que iria gaguejar. É válido ressaltar que P. sempre referia gaguejar no significante "palavra" e isso nos fez pensar na representação inconsciente que esse significante remete, ou seja, "palavra" para ele é a fluência desejada que ele acredita não ter, é o desejo inacessível, por isso sempre evitado e substituído por outros significantes sem carga emocional associada. Percebe-se também que P. nunca gagueja na palavra "dificuldade" haja vista que para ele é 
rotineiro sentir dificuldades, ele se considera possuidor de dificuldades na fala e talvez por isso não gagueje.

Em T3 a terapeuta busca a abertura do discurso e o deslizamento no eixo metonímico o que ocorre em P5 quando P. tenta tornar seu discurso mais claro para o interlocutor. Em T 4 e T5 a terapeuta continua buscando o deslizamento no eixo metonímico e o deslocamento discursivo de P. que pode ser visivelmente atestado em P8 quando ele seleciona mais um significante "truque" e o combina com o significante "força".

Também neste recorte percebe-se que a fala da terapeuta promove vários deslocamentos discursivos na fala de P., que faz novas seleções e combinações com o objetivo de tornar seu discurso mais claro para o interlocutor. Mas uma vez é válido ressaltar que o discurso não é transparente e o sujeito precisa ter seus significantes (re) significados para que possam circular e fazer sentido em determinado contexto discursivo.

\section{Recorte Discursivo 3:}

T7: Como é que é assim essa força que você fala? É uma força que você faz na hora de falar, é uma força que você coloca aqui na garganta como é que é?

P9: É__é como se fosse um bloqueio né, na hora eu vôf___ eu vô fala e tem eu / eu / eu forço um pouco e / e / e / a ela sai.

Em T7 a terapeuta busca a abertura da metáfora "força", porém logo em seguida faz uma colocação indutiva e localiza a gagueira no sujeito com o significante "garganta", aprisionando neste significante. O sujeito não se desloca e em P9 provavelmente troca um possível significante “palavra” por “ela”, mantendo-se preso à língua (forma).

Neste recorte podemos observar que a intervenção da terapeuta não surtiu efeito na fala de P., pois para ele não foi possível selecionar e combinar seus próprios significantes, visto que ele já havia sido "pré-selecionado" pela terapeuta (significante "garganta”). Sendo assim, P. permanece preso ao significante "bloqueio" que já havia aparecido em recortes que antecederam este, e não se desloca de sua posição discursiva, continua preso à forma.

\section{Recorte Discursivo 4:}

P10: É_é/é/é/é__ assim__ é/é__ quan__do eu__ vou_falar__élé/é como se___ se___ fica___sse __ presa a palavra aí eu tenho que botar uma força pra/pra vê se sai/sai é__ normalmente.

$\mathrm{T}$ : Você tem que botar uma força para a palavra sair? 
P:é

Em P10, P. utiliza pela primeira vez na sessão o significante "presa" referindo-se a "palavra" para explicar o que ocorre quando acontece o bloqueio. Em T8 a terapeuta não busca deslocar esta metáfora, detendo-se no significante "força" que já havia sido selecionado várias vezes no discurso de P. Neste caso, o sujeito é silenciado pelas condições de produção, onde não lhe foi permitido deslizar nos eixos de funcionamento da linguagem.

\section{CONCLUSÃO}

Após a análise dos recortes, pudemos observar que no trabalho discursivo é preciso que estejamos atentos ao discurso do sujeito gago e a todos os significantes em circulação; promovendo abertura de metáforas e deslizamento nos eixos de funcionamento da linguagem, neste caso especialmente no eixo metonímico, como nos dois primeiros recortes aqui ilustrados.

Pode-se perceber que, mesmo no trabalho discursivo, existem momentos em que o sujeito é silenciado ou modifica seu dizer, por conta das condições de produção. Nós fonoaudiólogos, precisamos estar atentos para que a clínica seja lugar de (re)significação constante, onde a linguagem não é transparente e os significantes precisam ser postos em circulação, para que o sujeito gago possa se desaprisionar da língua e deslizar "fluentemente" no eixo da fala.

\section{REFERÊNCIAS}

AZEVEDO, N. P. S. G. Uma análise discursiva da gagueira: da alienação na língua ao silenciamento. 2000. 127f. Dissertação (Mestrado em Fonoaudiologia) - Pontifícia Universidade Católica de São Paulo, São Paulo, 2000.

; FREIRE, R. M. Trajetórias de silenciamento e aprisionamento na língua: o sujeito, a gagueira e o Outro. In: FRIEDMAN, S.; CUNHA, M.C. (Org.). Gagueira e subjetividade: possibilidades de tratamento. Porto Alegre: Artmed, 2003. p. 145-160.

DE LEMOS, C. T. G. Desenvolvimento da linguagem e processo de subjetivação. Campinas: DL-IEL-UNICAMP, 1999. 27p.

Língua e discurso na teorização sobre aquisição da linguagem. Letras de hoie. Porto Alegre, v.30, n. 4, p. 9-28. 1995.

Los processos metafóricos y metonímicos como mecanismos de cambio.

Substratum, n.1, p. 121-135. 1992.

(C) ETD - Educação Temática Digital , Campinas, v.9, n.1, p.361-374, dez. 2007 - ISSN: 1676-2592. 


\section{Área Temática: Diferenças e Subjetividades}

Processos metafóricos e metonímicos: seu estatuto descritivo e explicativo na aquisição da língua materna. São Paulo, 1999. (Mimeogr.).

Uma abordagem sócio-construtivista da aquisição de linguagem: um percurso e muitas questões. In: ENCONTRO NACIONAL DE AQUISIÇÃO DA LINGUAGEM, 1, 1989, Porto Alegre. [Anais...] Porto Alegre:[s.n.], 1989. p.61-76.

Sobre aquisição de linguagem e seu dilema (pecado) original. Boletim da

Abralin, Recife, n. 3 , p. 11-23. 1982.

DOR, J. Introdução à leitura de Lacan._Porto Alegre: Artes Médicas. 1992.

LlER-DE-VITTO, M. F. Os monólogos da criança: delírios na língua. São Paulo: EDUC, 1998. p. 22.

ORLANDI, E. Interpretação: autoria, leitura e efeitos do trabalho simbólico. Vozes: Rio de Janeiro, 1996. p.22.

SAUSSURE, F. Curso de lingüística geral. Cultrix: São Paulo. 1987. 
Graduada em Fonoaudiologia pela Universidade Católica de Pernambuco - UNICAP, em Psicologia pela Universidade Federal de Pernambuco UFPE e Especializada em Patologias da Linguagem pela UNICAP. Atualmente Mestranda em Letras na Universidade Federal da Paraíba UFPB. Tem experiência como Intérprete de Língua Brasileira de Sinais e em fonoterapia, atuando principalmente nas áreas de linguagem e audiologia educacional. Email: ariomarvalle@hotmail.com

MARIA JANAINA ALENCAR SAMPAIO

Fonoaudióloga graduada pela UNICAP; com Especialização em Patologias da Linguagem - UNICAP; Psicóloga graduada pela UFPE; mestranda em Letras pela UFPB. Email: janainafono@yahoo.com.br

Artigo recebido em: $18 / 10 / 2006$ Artigo para publicação em: 20/12/2007 